\title{
ARGUMENTAÇÃO JURÍDICA, PONDERAÇÃO E REPRESENTATIVIDADE ARGUMENTATIVA NA OBRA DE ROBERT ALEXY / JURIDICAL ARGUMENTATION, BALANCING OF INTERESTS AND REPRESENTATIVE ARGUMENTATION AT WORK OF ROBERT ALEXY
}

\author{
Mauricio Jorge Pereira da Mota \\ Professor Adjunto da Faculdade de Direito da Universidade do Estado do Rio de Janeiro - UERJ. \\ Procurador do Estado do Rio de Janeiro. Doutor em Direito Civil pela Universidade do Estado do Rio de \\ Janeiro - UERJ. \\ Daniel Queiroz Pereira \\ Professor Assistente da Escola de Ciências Jurídicas da Universidade Federal do Estado do Rio de Janeiro \\ - UNIRIO. Assistente de pesquisas da Editora Atlas S.A. Advogado. Bacharel, Mestre e Doutor em \\ Direito da Cidade pela Universidade do Estado do Rio de Janeiro - UERJ. Pós-graduado em Direito \\ Material e Processual do Trabalho pela Universidade Gama Filho - UGF.
}

Resumo: O objetivo principal deste artigo reside em expor a teoria da argumentação jurídica de Robert Alexy, que se afigura como uma teoria procedimental, formada por um sistema de regras e voltada à correção dos enunciados normativos, bem como sua importância na seara dos direitos fundamentais. Trata-se de tema de extremo relevo para a Filosofia do Direito e o Constitucionalismo Democrático. Para tanto, empregou-se o método teórico-conceitual e descritivo-interpretativo, mediante a interpretação crítica dos principais aspectos observados em relação ao tema. A partir de tal investigação, constatou-se que associar a argumentação jurídica a um ensino mais "prático" do Direito não pode culminar na aceitação acrítica do Direito. Daí exigir-se, além da existência de uma justificação interna, uma preocupação com a validade das premissas usadas na justificação (justificação externa) no âmbito do discurso jurídico. No que tange à interpretação dos direitos fundamentais, percebeu-se que considerá-los, à luz do princípio da proporcionalidade, significa tratá-los como princípios, já que demandarão que algo se realize com a maior amplitude possível dentro das possibilidades jurídicas e fáticas, adquirindo também aqui importância o estudo da argumentação jurídica, pois as decisões ou proposições conectadas pela "fórmula do peso", proposta por Alexy, devem ser justificadas mediante ulteriores argumentos.

Palavras-chave: argumentação jurídica; direitos fundamentais; ponderação.

\begin{abstract}
The main objective of this article is to expose Robert Alexy's legal argumentation theory, which consists in a procedural theory, constituted by a system of rules and that seeks the correctness of normative standards, as well as it's relevance to the fundamental rights. It is a very important theme for Philosophy of Law and Democratic Constitutionalism. In order to do that, we used the theoreticalconceptual and descriptive-interpretative methods, through the critical interpretation of the main aspects related to the theme. Through this research, we could notice that the association between legal argumentation and a more "practical" teaching of law can't lead to an uncritical acceptation of Law. So, besides the existence of an internal justification, there must exist a preoccupation with the validity of the premises used in that justification (external justification) in the field of juridical discourse. On what refers to the fundamental rights, we could notice that studying them, on the focus of the proportionality principle, means to consider them as principles, as they will require that something takes place with the greatest amplitude possible as determined by the juridical and factual possibilities, being important inclusive here the study of legal argumentation as the decisions or propositions connected by the "weight formula", proposed by Alexy, must be justified through others arguments.
\end{abstract}

Key-words: legal argumentation; fundamental rights; ponderation.

Revista Quaestio luris, vol.05, n-01. ISSN 1516-0351 p. 21-50 21 
Sumário: I - Introdução: o modelo de regras e princípios e as normas de direitos fundamentais; II - A argumentação jurídica; II.1 - A justificação interna; II.2 - A justificação externa; III - Críticas à argumentação jurídica na obra de Robert Alexy; IV - Ponderação e representação argumentativa; V Conclusão; VI - Referências.

\title{
I $\quad$ - Introducão: o modelo de regras e princípios e as normas de direitos
}

\section{fundamentais}

A distinção entre regras e princípios constitui a estrutura de uma teoria normativo-material dos direitos fundamentais e, com isso, um ponto de partida para a resposta à pergunta acerca da possibilidade e dos limites da racionalidade no âmbito dos direitos fundamentais. Salientando a importância de tal distinção, afirma Robert Alexy que:

\begin{abstract}
Essa distinção é a base da teoria da fundamentação no âmbito dos direitos fundamentais e uma chave para a solução de problemas centrais da dogmática dos direitos fundamentais. Sem ela não pode haver nem uma teoria adequada sobre as restrições a direitos fundamentais, nem uma doutrina satisfatória sobre colisões, nem uma teoria suficiente sobre o papel dos direitos fundamentais no sistema jurídico. Essa distinção constitui um elemento fundamental não somente da dogmática dos direitos de liberdade e igualdade, mas também dos direitos a proteção, a organização e procedimento e a prestações em sentido estrito. Com sua ajuda, problemas como os efeitos dos direitos fundamentais perante terceiros e a repartição de competências entre tribunal constitucional e parlamento podem ser mais bem esclarecidos ${ }^{1}$.
\end{abstract}

Princípios são, tanto quanto as regras, razões para juízos concretos de dever-ser.

Deste modo, a distinção entre princípios e regras consiste em uma distinção entre duas espécies de normas ${ }^{2}$. Entretanto, a despeito de sua longevidade e de sua utilização freqüente, a distinção entre regras e princípios padece de falta de clareza e suscita polêmicas.

\footnotetext{
${ }^{1}$ ALEXY, Robert. Teoria dos direitos fundamentais. Tradução de Virgílio Afonso da Silva. São Paulo: Malheiros, 2008, p. 85. 2

“Com freqüência, não são regra e princípio, mas norma e princípio ou norma e máxima, que são contrapostos. Aqui, regras e princípios serão reunidos sob o conceito de norma. Tanto regras quanto princípios são normas, porque ambos dizem o que deve ser. Ambos podem ser formulados por meio das expressões deônticas básicas do dever, da permissão e da proibição. Princípios são, tanto quanto as regras, razões para juízos concretos de dever-ser, ainda que de espécie muito diferente. A distinção entre regras e princípios é, portanto, uma distinção entre duas espécies de normas”. ALEXY, Robert. Teoria dos direitos fundamentais. Tradução de Virgílio Afonso da Silva. São Paulo: Malheiros, 2008, p. 87.
} 
Há diversos critérios que tradicionalmente são apontados para realizar tal distinção: generalidade; determinabilidade dos casos de aplicação; diferenciação entre "normas de comportamento" e "normas de argumentação" etc.

Contudo, o ponto decisivo na distinção entre regras e princípios é que princípios são normas que ordenam que algo seja realizado na maior medida possível dentro das possibilidades jurídicas e fáticas existentes. Deste modo, os princípios são "mandamentos de otimização",2, que se caracterizam por poderem ser satisfeitos em graus variados e pelo fato de que a medida devida de sua satisfação não depende somente das possibilidades fáticas, mas também das possibilidades jurídicas. $\mathrm{O}$ âmbito das possibilidades jurídicas é determinado pelos princípios e regras colidentes.

Já as regras são normas que são sempre ou satisfeitas ou não satisfeitas. Se uma regra vale, deve-se fazer precisamente aquilo que ela exige. As regras contêm, pois, determinações no âmbito daquilo que é fática e juridicamente possível. Isso significa que a distinção entre regras e princípios é uma distinção qualitativa e não de grau.

Diante desta distinção, salienta Alexy que emerge um distinto caráter prima facie das regras e dos princípios:

Princípios exigem que algo seja realizado na maior medida possível dentro das possibilidades jurídicas e fáticas existentes. Nesse sentido, eles não contêm um mandamento definitivo, mas apenas prima facie. Da relevância de um princípio em um determinado caso não decorre que o resultado seja aquilo que o princípio exige para esse caso. Princípios representam razões que podem ser afastadas por razões antagônicas. A forma pela qual deve ser determinada a relação entre razão e contra-razão não é algo determinado pelo próprio princípio. Os princípios, portanto, não dispõem da extensão de seu conteúdo em face dos princípios colidentes e das possibilidades fáticas. $\mathrm{O}$ caso das regras é totalmente diverso. Como as regras exigem que seja feito exatamente aquilo que elas ordenam, elas têm uma determinação da extensão de seu conteúdo no âmbito das possibilidades jurídicas e fáticas; mas, se isso não ocorrer, então, vale definitivamente aquilo que a regra prescreve.

Diante disso, alguém poderia imaginar que os princípios têm sempre um mesmo caráter prima facie, e as regras um mesmo caráter definitivo. Um tal modelo parece estar presente em Dworkin, quando ele afirma que regras, se válidas, devem ser aplicadas de forma tudo-ou-nada, enquanto os princípios apenas contêm razões que indicam uma direção, mas não têm como consequiência necessária uma determinada decisão ${ }^{3}$. Esse modelo é, contudo, muito simples. Um modelo diferenciado é necessário. Mas também no

\footnotetext{
${ }^{2}$ ALEXY, Robert. Teoria dos direitos fundamentais. Tradução de Virgílio Afonso da Silva. São Paulo: Malheiros, 2008, p. 90.

${ }^{3}$ DWORKIN, Ronald. Taking Rights Seriously. 2 ed. Londres: Duckworth, 1978, pp. 24 e 26.
} 
âmbito desse modelo diferenciado o diferente caráter prima facie das regras e dos princípios deve ser mantido ${ }^{4}$.

Neste passo, o caráter prima facie dos princípios pode ser fortalecido por meio da introdução de uma carga argumentativa a favor de determinados princípios ou de determinadas classes de princípios, conforme melhor se verá adiante.

De pronto, o que se constata é que, através das disposições de direitos fundamentais, são estatuídas duas espécies de normas: as regras e os princípios. Este é o fundamento do caráter duplo das disposições de direitos fundamentais. Contudo, isto não significa que as normas de direitos fundamentais compartilham desse mesmo caráter duplo.

De início elas são ou regras (normalmente incompletas) ou princípios. Mas as normas de direitos fundamentais adquirem um caráter duplo se forem construídas de forma a que ambos os níveis sejam nela reunidos. Uma tal vinculação de ambos os níveis surge quando na formulação da norma constitucional é incluída uma cláusula restritiva com a estrutura de princípios, que, por isso, está sujeita a sopesamentos.

$[\ldots]$

Mesmo normas dotadas de reserva qualificada [regras] necessitam de uma transformação complementadora, o que faz com que nelas seja incorporada a máxima da proporcionalidade e, com isso, uma parte da teoria dos princípios. Sua peculiaridade consiste na limitação do espectro dos princípios colidentes por meio de determinações no nível das regras ${ }^{5}$.

Trata-se, portanto, de adotar, no que se refere às hipóteses de conflitos entre normas de direitos fundamentais, uma postura semelhante àquela da solução de conflitos entre princípios, isto é, recorrer-se à ponderação, ao sopesamento, mais especificamente, à máxima da proporcionalidade em sentido estrito. Nas palavras de Robert Alexy:

Princípios são mandamentos de otimização em face das possibilidades jurídicas e fáticas. A máxima da proporcionalidade em sentido estrito, ou seja, exigência de sopesamento, decorre da relativização em face das possibilidades jurídicas. Quando uma norma de direito fundamental com caráter de princípio colide com um princípio antagônico, a possibilidade jurídica para a realização dessa norma depende do princípio antagônico. Para se chegar a uma decisão é necessário um sopesamento nos termos da lei de colisão ${ }^{6}$.

\footnotetext{
${ }^{4}$ ALEXY, Robert. Teoria dos direitos fundamentais. Tradução de Virgílio Afonso da Silva. São Paulo: Malheiros, 2008, pp. 103-104.

${ }^{5}$ ALEXY, Robert. Teoria dos direitos fundamentais. Tradução de Virgílio Afonso da Silva. São Paulo: Malheiros, 2008, pp.141-144.

${ }^{6}$ ALEXY, Robert. Teoria dos direitos fundamentais. Tradução de Virgílio Afonso da Silva. São Paulo: Malheiros, 2008, p. 117.
} 
Buscar-se-á, a partir do tópico seguinte, demonstrar como a teoria da argumentação jurídica, tal qual proposta por Alexy, contribui para a consecução deste desiderato.

\section{II - A argumentacão jurídica}

Um dos únicos pontos sobre o qual existe acordo na metodologia jurídica contemporânea ${ }^{7}$ é o de que a decisão jurídica, que põe fim a uma disputa, em muitos casos, não deriva diretamente das normas jurídicas existentes, deixando uma margem de ação para aquele que decide, uma vez que deverá escolher entre várias soluções possíveis.

Para Alexy, as valorações não implicam na existência de um campo livre, de puro arbítrio, para a manifestação de convicções subjetivas por parte daquele que deve decidir o caso.

Neste sentido, a questão da racionalidade da fundamentação jurídica está ligada à possibilidade de se fundamentar racionalmente os juízos práticos em geral, uma vez que a questão sobre a decisão correta em determinado caso se refere exatamente àquilo que é devido nesta situação ${ }^{8}$.

Acerca da importância que a argumentação jurídica adquiriu no âmbito da cultura jurídica ocidental afirma Manuel Atienza que isto se verificou em virtude da passagem do "Estado legislativo" para o "Estado constitucional".

Por Estado constitucional, como es obvio, no se entiende simplesmente el Estado en el que está vigente una Constitución, sino el Estado en el que la Constitución (que pude no serlo en sentido formal: puede no haber un texto constitucional) contiene: a) un principio dinámico del sistema jurídico político, o se ala distribución formal del poder entre los diversos órganos estatales (Aguiló 2002), b) ciertos derechos fundamentales que limitan o condicionan (también en cuanto al contenido) la producción, la interpretación y la aplicación del derecho, c) macanismos de control de la constitucionalidad de las leyes. Como consecuencia, el poder del legislador (y el de cualquier órgano estatal) es um poder limitado y tiene que justificarse en forma mucho más exigente. [...] El Estado constitucional supone así un incremento en cuanto a la tarea justificativa de los órganos públicos y, por tanto, uma mayor demanda de argumentación jurídica (que la requerida por el Estado liberal - legislativo - de derecho). En realidad, el ideal del Estado constitucional (la culminación del Estado de derecho) supone el sometimiento completo del poder al derecho, a la razón: la fuerza

\footnotetext{
${ }^{7}$ LARENZ, Karl. Metodologia Jurídica. Lisboa: Calouste Gulbenkian, 1989.

${ }^{8}$ FERREIRA, Fernando Galvão de Andréa. "O discurso jurídico como discurso prático: aspectos do debate entre Robert Alexy e Jürgen Habermas". In: Revista da Faculdade de Direito de Campos, ano VII, $\mathrm{n}^{\circ} 9$ - dezembro de 2006, p. 88
} 
de la razón, frente a la razón de la fuerza. Parece, por ello, bastante lógico que el avance del Estado constitucional haya ido acompañado de um incremento cuantitativo y cualitativo de la exigencia de justificación de las decisiones de los órganos públicos ${ }^{9}$.

Neste particular, adquire especial relevo a teoria da argumentação jurídica esposada por Alexy que se afigura como uma teoria procedimental, formada por um sistema de regras, cujo objetivo reside na correção dos enunciados normativos.

Considera o autor que o discurso jurídico é um caso especial do discurso prático geral, já que as discussões jurídicas se preocupam com questões práticas, isto é, com o que deve ou não ser feito ou deixado de fazer e essas questões são discutidas com a exigência de correção ${ }^{10}$, conforme já se mencionou. Os juízes têm o dever de justificar suas decisões. Isso coloca as decisões judiciais sob a exigência da correção em virtude da lei positiva. Desta forma, um ponto pode ser estabelecido $a b$ initio: a argumentação jurídica é caracterizada por seu relacionamento com a lei válida; contudo, isso precisa ser determinado. Esta teoria apresenta como fio condutor, portanto, a tensão entre facticidade e validade ou, mais especificamente, entre o princípio da segurança jurídica e a pretensão à correção das decisões.

Luhman considera necessário "que os não participantes cheguem a uma convicção de que nada de estranho está acontecendo, de que a verdade e a justiça estão sendo estabelecidos com esforço sério, sincero e árduo e que eles também, se for necessário, terão assegurados seus direitos pelo recurso a esta instituição ${ }^{12}$.

Isso evidencia que a teoria do discurso racional como teoria de argumentação jurídica não só pressupõe que todas as disputas jurídicas devem ser vistas como discursos no sentido de comunicação direta não coercitiva, mas também que, em disputas jurídicas, a discussão procede sob a exigência de correção e, segundo isso, por referência à situação ideal.

Neste ponto, salienta Manuel Atienza que a tendência à conformação de um direito mais "informal" (através da utilização de mecanismos como a conciliação, a

\footnotetext{
${ }^{9}$ ATIENZA, Manuel. "El derecho como argumentación”. In: ATIENZA, Manuel \& FERRAJOLI, Luigi. Jurisdicción y argumentación en el Estado constitucional de derecho. São Paulo: Landy, 2000, pp. 10-11. ${ }^{10}$ Neste particular, afirma Fernando Galvão de Andréa Ferreira que, partindo da teoria do discurso racional, "Alexy desenvolve a tese de que o discurso jurídico é um caso especial do discurso prático geral, ou seja, uma atividade lingüística, guiada por regras, com a qual se objetiva a correção de enunciados normativos. O discurso jurídico se distingue, porém, das demais formas de discurso, pelo fato de estar
} 
mediação, a negociação) supõe um aumento do elemento argumentativo (ou "retórico") do direito frente ao elemento burocrático e coativo ${ }^{13}$.

Assim sendo, pode-se apontar como traços básicos de uma teoria de argumentação jurídica, em primeiro lugar, que os discursos jurídicos se relacionam com a justificação de um caso especial de afirmações normativas, isto é, aquelas que expressam julgamentos jurídicos; e, em segundo lugar, que dois aspectos da justificação podem ser distinguidos: a) justificação interna (internal justification) relacionada à questão de se uma opinião segue logicamente das premissas aduzidas para justificá-la; b) justificação externa (external justification) em que se perquire a correção das premissas utilizadas no processo de justificação interna.

submetido a uma série de condições limitadoras, como por exemplo: sujeição à lei, a consideração dos precedentes, etc". FERREIRA, Fernando Galvão de Andréa. "O discurso jurídico como discurso prático: aspectos do debate entre Robert Alexy e Jürgen Habermas". In: Revista da Faculdade de Direito de Campos, ano VII, n 9 - dezembro de 2006, p. 88.

12 ALEXY, Robert. Teoria da argumentação jurídica: a teoria do discurso racional como teoria da justificação jurídica. São Paulo, Landy, 2001, p. 215.

${ }^{13}$ ATIENZA, Manuel. "El derecho como argumentación”. In: ATIENZA, Manuel \& FERRAJOLI, Luigi. Jurisdicción y argumentación en el Estado constitucional de derecho. São Paulo: Landy, 2000, p. 12.

\section{II.1 - A justificacão interna}

Os problemas associados à justificação interna foram amplamente discutidos sob o título "silogismo jurídico". Além disso, há uma série de publicações que lidam com esta área problemática aplicando-se os métodos da lógica moderna.

A forma mais simples de justificação interna tem a seguinte estrutura:

(J.1.1) . (1) (x) (Tx $\rightarrow$ ORx $)$

. (2) Ta

(3) Ora (1), (2)

" $x$ " é uma variável individual sobre o campo das pessoas naturais e jurídicas, "a" é uma constante individual, por exemplo, um nome próprio; "T" é um predicado em qualquer nível escolhido de complexidade apropriado para abranger os fatos operativos da norma (1) como uma característica das pessoas; e "R" é um predicado analogamente complexo que expressa o que o implicado na questão tem de fazer.

Há questões legais a respeito das quais uma justificação da forma (J.1.1) é suficiente. Um exemplo disso seria:

(1) Soldados em missão oficial têm de dizer a verdade (par. 13, seção 1, regulamento militar alemão).

(2) O Sr. M é um soldado. 
(3) O Sr. M tem de dizer a verdade quando em missão oficial (1) (2) ${ }^{11}$

Trata-se, pois, de, partindo de uma premissa que justifique o requerimento de justificação através das regras universais estabelecidas pelo princípio da universalizabilidade $^{12}$ (J.1.1), estabelecer uma multiplicidade de passos que leve à clareza. Ressalte-se que não há, neste momento, uma preocupação com a validade das premissas usadas na justificação, pois este é o objeto tema da justificação externa.

Surgem, portanto, como regras de justificação interna e, conseqüentemente, mecanismos de concretização do princípio da universalizabilidade:

a) ao menos uma norma universal precisa ser aduzida na justificação de um julgamento jurídico;

b) um julgamento jurídico precisa seguir logicamente ao menos uma norma universal juntamente com outras afirmações;

c) tal como o princípio da universalizabilidade, não devem ser superestimados. Eles não estabelecem nada sobre o conteúdo da norma universal, nem excluem a possibilidade de mudar a norma universal, por exemplo, introduzindo exceções. Mas essas exceções, por sua vez, têm de ser de aplicação universal. As premissas que, juntamente com as demais condições estipuladas, se verifiquem como suficientes para justificar o julgamento jurídico, podem ser compreendidas como regras para o uso de expressões utilizadas em estágios anteriores de justificação e podem ser denominadas "regras do uso da palavra".

Diante do exposto surge a questão de como a decomposição em vários passos é necessária. Para explicá-la, Alexy formula duas regras:

O número de passos de desenvolvimento requerido é o número que torna possível o uso de expressões cuja aplicação em dado caso não admita posterior disputa.

[...]

Quando há poucos e muitos amplos passos de desenvolvimento, seu conteúdo normativo deixa de aparecer com muita clareza. Por outro lado,

\footnotetext{
${ }^{11}$ ALEXY, Robert. Teoria da argumentação jurídica: a teoria do discurso racional como teoria da justificação jurídica. São Paulo, Landy, 2001, p. 218.

12 “O princípio da universalizabilidade está por trás do princípio da justiça formal. O princípio da justiça formal requer o cumprimento de uma 'regra que estabeleça a obrigação de tratar de certo modo todas as pessoas que pertencem a dada categoria. Trata-se de exigência do cumprimento de uma norma numa justificação jurídica em que, como no caso de (J.1.1), o julgamento jurídico segue logicamente desta regra. Caso contrário, seria possível aduzir uma regra no curso da justificação, e, no entanto, afirmar qualquer conclusão. As regras seguintes de justificação interna podem assim ser formuladas como uma concretização do princípio de universalizabilidade". ALEXY, Robert. Teoria da argumentação jurídica: a teoria do discurso racional como teoria da justificação jurídica. São Paulo, Landy, 2001, p. 219.
} 
ficam facilmente abertos ao ataque, por outro lado esse ataque muitas vezes não é específico. Uma multiplicidade de passos pode ser trabalhosa mas leva à clareza. Portanto, [...] Tantos passos de desenvolvimento quanto possíveis devem ser articulados.

As regras e formas descobertas até aqui dizem respeito à estrutura da justificação jurídica. Sua ênfase está em assegurar a universalizabilidade. Portanto, elas podem ser chamadas "regras e formas de justiça formal"l3.

Deve-se ainda salientar que, por vezes, as premissas utilizadas na argumentação jurídica não derivam da lei positiva e, através da referida decomposição, são trazidas à luz.

\section{II.2 - A justificacão externa}

A justificação de premissas usadas no processo de justificação interna é o assunto da justificação externa.

Estas premissas podem ser: a) regras da lei positiva; b) afirmações empíricas; c) premissas que não são nem afirmações empíricas nem regras da lei positiva.

Correspondendo a estes diferentes tipos de premissas há os diferentes métodos de justificação:

a) a justificação de uma regra como regra da lei positiva ocorre mostrandose

que atende os critérios de validade da ordem jurídica;

b) na justificação de premissas empíricas uma série de procedimentos pode ser usada, que vão desde métodos das ciências empíricas até máximas de presunção racional às regras que têm o encargo de prova em um processo;

c) as premissas que não são nem afirmações empíricas nem regras da lei positiva são justificadas pela "argumentação jurídica" ou "argumentação legal”.

Há de fato muitas relações diretas entre esses três procedimentos de justificação. Essas regras da lei positiva e as afirmações empíricas representam um papel importante na justificação das premissas que nem são matéria da lei positiva nem empírica. Ao justificar a norma segundo critérios de validade ou de ordem legal pode ser necessário interpretar as regras que definem os critérios de validade. Isso é de particular importância onde houver limitações constitucionais entre os critérios de validade, por exemplo, uma lista de direitos fundamentais. A argumentação jurídica pode ser de decisivo significado não só na interpretação da norma válida mas também ao estabelecer sua validade. Certamente, isso também é verdadeiro

\footnotetext{
${ }^{13}$ ALEXY, Robert. Teoria da argumentação jurídica: a teoria do discurso racional como teoria da justificação jurídica. São Paulo, Landy, 2001, pp. 222-223.
} 
para o estabelecimento de fatos empíricos. Assim, o que é admitido na justificação como um fato pode depender da interpretação de uma regra com valor de prova. É justamente por causa desse 'cruzamento' que, a menos que alguém queira juntar algo, há necessidade de distinguir cuidadosamente entre os três métodos antes mencionados de justificação. Somente dessa maneira se torna possível analisar o inter-relacionamento entre eles ${ }^{14}$.

No que tange à justificação das premissas que nem são regras de lei positiva nem afirmações empíricas, pode-se apontar, numa classificação rudimentar, as seguintes formas de argumento e regras de justificação externa: a) interpretação; b) argumentação dogmática; c) uso de precedentes; d) argumentação geral prática; e) argumentação empírica; f) as formas especiais de argumentos jurídicos.

A argumentação empírica, especificamente, adquire importância em virtude do fato de que quase todas as formas de argumento jurídico incluem afirmações empíricas.

Tais afirmações podem versar sobre fatos particulares, ações individuais e motivos dos agentes ou ainda pode-se fazer necessário realizar uma distinção entre afirmações sobre ações passadas, presentes e futuras, eventos ou estados de coisas. Neste caso, essas afirmações podem ser feitas em diferentes campos de conhecimento tais como a economia, sociologia, psicologia, medicina, lingüística etc ${ }^{15}$.

Nesta esteira, facilmente se constata que uma teoria exaustiva da argumentação empírica relevante para a justificação jurídica teria de lidar com quase todos os problemas do conhecimento empírico. Além disso, há os problemas de incorporações de conhecimento empírico na argumentação jurídica, que só serão resolvidos por meio de cooperação interdisciplinar.

Deste modo, assim como acontece na seara do discurso prático geral, também no âmbito do discurso jurídico pode-se perceber que o necessário conhecimento empírico muitas vezes não está disponível com o desejado grau de certeza. Essa situação requer, pois, regras de presunção racional e que a relevância do conhecimento empírico para a argumentação jurídica não seja superestimada.

\footnotetext{
${ }^{14}$ ALEXY, Robert. Teoria da argumentação jurídica: a teoria do discurso racional como teoria da justificação jurídica. São Paulo, Landy, 2001, p. 225.

${ }^{15}$ Em crítica ao atual estado da argumentação jurídica, afirma Manuel Atienza que a teoria da argumentação jurídica de nossos dias se ocupa, quase exclusivamente, do discurso justificativo dos juízes, isto é, das razões que oferecem como fundamento - motivação - de suas decisões (o contexto da justificação das decisões) e não da descrição e explicação dos processos de tomada de decisão (contexto do descobrimento) que exigiriam levar em consideração fatores de caráter econômico, ideológico etc. ATIENZA, Manuel. "El derecho como argumentación”. In: ATIENZA, Manuel \& FERRAJOLI, Luigi. Jurisdicción y argumentación en el Estado constitucional de derecho. São Paulo: Landy, 2000, p. 05.
} 
Desta forma, embora se dê alguma ênfase à importância dos argumentos empíricos, o foco principal reside no relacionamento das formas de argumento práticas gerais e jurídicas. Robert Alexy busca analisar este inter-relacionamento das diferentes formas de argumento a partir desta perspectiva e, para tanto, faz alusão aos denominados cânones de interpretação ${ }^{16}$.

Os referidos cânones de interpretação são classificados em seis grupos:

a) argumento semântico: pode ser usado para justificar ou criticar uma interpretação ou para mostrar que, ao menos semanticamente, é admissível;

b) argumento genético: justifica uma dada interpretação ao afirmar que essa interpretação corresponde à intenção do legislador ${ }^{20}$;

c) argumento histórico: é um termo usado para os casos em que os fatos relativos à história dos problemas jurídicos em discussão são oferecidos como razões a favor ou contra alguma decisão interpretativa;

d) argumento comparativo: se faz referência não só a algum estado legal de coisas do passado, mas muito mais a algum estado de outra sociedade. Essa forma de argumento inclui, ao menos, uma premissa normativa, bem como muitas premissas empíricas;

e) argumento sistemático: é uma expressão usada como referência tanto para a posição de uma norma no texto jurídico, quanto para a relação lógica e teleológica de

\footnotetext{
${ }^{16}$ SAVIGNY, Friedrich Carl von. System des heutigen Römischen Rechts. vol. I. Berlim, 1840, pp. 212 ss. 20

“As formas de interpretação semântica incluem afirmações sobre a validade das regras semânticas, enquanto que as da interpretação genética incluem afirmações sobre a intenção do legislador. Muitas vezes essas afirmações não são explícitas. Simplesmente se afirma que certa interpretação corresponde ao texto da norma, à vontade do legislador ou ao propósito da norma. Nesses casos o argumento é incompleto. A fim de completá-lo, requer-se afirmações do tipo citado acima. Isso será chamado de 'exigência de saturação'. A solidez dos argumentos em suas várias formas depende da solidez das afirmações que têm de ser inseridas para atender essa exigência. Outras formas de argumentos são necessárias para justificar a solidez dessas afirmações”. ALEXY, Robert. Teoria da argumentação jurídica: a teoria do discurso racional como teoria da justificação jurídica. São Paulo, Landy, 2001, p. 231. (Grifei)
} 
uma norma com outras normas, objetivos e princípios;

f) argumento de interpretação teleológica: pressupõe uma análise detalhada dos conceitos de fins e meios bem como dos conceitos correspondentes de desejo, intenção, necessidade prática e objetivo.

\begin{abstract}
As diferentes formas preenchem diferentes funções. As formas de argumentação semântica e genética se relacionam como o compromisso de quem toma decisões com as próprias palavras do estatuto e com a intenção do legislador respectivamente. As formas histórica e comparativa permitem o aprendizado com as experiências do passado e com outras sociedades. A interpretação sistemática contribui, entre outras coisas, para libertar a ordem jurídica da contradição. Finalmente, as formas teleológicas abrem campo para a argumentação prática geral. Tudo isso caracteriza apenas uma função particularmente importante das várias formas em cada caso ${ }^{17}$.
\end{abstract}

Mais do que isso, os argumentos que usam uma forma podem nos levar a solução bastante diferente dos argumentos que usem outra forma. Deve-se salientar que não existe ordem hierárquica definida das diferentes formas. Elas estão numa relação de reciprocidade e seu respectivo peso não é, em última análise, determinado pelos resultados que oferecem em casos individuais ${ }^{18}$.

A teoria do discurso contribui, assim, para a resolução dos problemas na medida em que indica como as diferentes formas de argumento podem ser empregadas utilmente. Regras e formas são estabelecidas cuja observação e implementação aumenta a probabilidade de atingir um resultado racional ou razoável em qualquer discussão. Não se pode dizer com base nessas regras e formas apenas quais devem ser os resultados. Isto requer uma discussão real ou imaginária.

Além disso, nenhum procedimento que garanta a certeza está à vista ainda. Qualquer pessoa que equipare racionalidade com certeza terá de renunciar à idéia de uma teoria da argumentação jurídica racional.

\footnotetext{
Resumindo, pode-se dizer que embora os cânones não ofereçam uma garantia de 'descobrir a resposta certa... com um grau relativamente alto de certeza', eles ainda assim são mais do que meros instrumentos para a legitimação de uma decisão que pode ser alcançada e justificada de modos alternativos. Trata-se de formas em que a argumentação jurídica tem de ser computada se for para atender sua exigência de correção, que, de forma
}

\footnotetext{
${ }^{17}$ ALEXY, Robert. Teoria da argumentação jurídica: a teoria do discurso racional como teoria da justificação jurídica. São Paulo, Landy, 2001, p. 237.

${ }^{18}$ LARENZ, Karl. Methodenlehre der Rechtswissenschaft. Berlim: Springer-Verlag, 1991, pp. 334 ss. 
diferente do que a do discurso prático geral, contém o reconhecimento da qualidade obrigatória da legislação ${ }^{19}$.

A argumentação dogmática, por sua vez, reclama a compreensão preliminar do que se entende por "dogmática jurídica" ou "dogmática legal”. Embora o consenso acerca do emprego da referida terminologia ainda não tenha sido alcançado, conforme posicionamento predominante entre os juristas, a expressão "dogmática jurídica” ou “dogmática legal” é aceita como significando ciência jurídica.

Essa ciência jurídica, no sentido mais estreito e apropriado, é uma mistura de ao menos três atividades:

a) aquela de descrever a lei em vigor (dimensão descritiva-empírica);

b) aquela de sujeitá-la a uma análise conceitual e sistemática (dimensão lógica-

analítica);

c) aquela de elaborar propostas sobre a solução própria do problema jurídico (dimensão normativa-prática).

Existem, portanto, três tarefas a serem desempenhadas pela dogmática: a análise lógica dos conceitos jurídicos, a unificação dessa análise em um sistema e a aplicação dos resultados obtidos para justificar decisões jurídicas.

Para a consecução de tal desiderato, diferentes argumentos dogmáticos (proposições da dogmática jurídica) podem ser empregues:

a) as definições de conceitos jurídicos autênticos, tais como aqueles dos contratos, dos atos administrativos e da autodefesa. O conteúdo desses conceitos depende das normas que regem a forma como os contratos vêm à existência, a operação dos atos administrativos e a solidez jurídica de um apelo de autodefesa. Significa dizer que, ausentes as normas às quais se referem, esses conceitos não significariam nada, mais do que isso, uma proposta para mudar um desses conceitos abrange também uma proposta para mudar as normas às quais se referem. É neste sentido que as definições de conceitos jurídicos autênticos têm conteúdo normativo ${ }^{20}$;

\footnotetext{
${ }^{19}$ ALEXY, Robert. Teoria da argumentação jurídica justificação jurídica. São Paulo, Landy, 2001, p. 236.

${ }^{20}$ ALEXY, Robert. Teoria da argumentação jurídica: a teoria do discurso racional como teoria da justificação jurídica. São Paulo, Landy, 2001, pp. 245-246. ${ }^{25}$ ALEXY, Robert. Teoria da argumentação jurídica justificação jurídica. São Paulo, Landy, 2001, p. 246. 


\section{Quaestio Iuris}

b) as definições de outros conceitos que ocorrem nas normas jurídicas. "Esses conceitos incluem aqueles como: 'ao realizar uma performance' no parágrafo 831, seção 1, sentença 1 do Código Criminal Alemão, ‘traiçoeiro' no parágrafo 211 do Código Criminal Alemão e 'área coerentemente elaborada' no parágrafo 34 do Código Federal de Construção da Alemanha ${ }^{25 "}$. Neste particular, parece que Alexy busca referir-se àquilo que se convencionou denominar na doutrina pátria de "conceitos jurídicos indeterminados". Como registrou Lourival Vilanova, "as normas são postas para permanecer como estruturas de linguagem, ou estruturas de enunciado, bastantes em si mesmas, mas reingressam nos fatos, de onde provieram, passando do nível conceptual e abstrato para a concrescência das relações sociais, onde as condutas são pontos ou pespontos do tecido social $^{21 "}$. Trata-se, pois, não apenas de uma questão semântica, mas também dogmática, uma vez, por vezes, a mera definição do conceito verifica-se insuficiente, devendo a mesma ser aceita ou, pelo menos, discutida no âmbito de uma ciência jurídica institucionalmente organizada;

c) as proposições dogmáticas não dogmáticas, isto é, as proposições que expressam uma norma que carece de qualquer "pedigree estatutário" 22 , tal como se verifica em relação à proposição de Staub para a instituição da violação positiva do contrato $^{23}$. Relembre-se que, para que uma proposição seja considerada dogmática, basta que a maioria dos especialistas considere que pertence à dogmática;

d) as descrições e designações de estados de coisas "cujo estabelecimento, término, ou preservação é suposto ser o propósito de normas individuais ou de grupos de normas bem como determinações de relações prioritárias entre esses estados de $\operatorname{coisas}^{24 \%}$;

e) a formulação de princípios. "Princípios são proposições normativas de um tão alto nível de generalidade que podem via de regra não ser aplicados sem o acréscimo de outras premissas normativas e, habitualmente, são sujeitos às limitações

\footnotetext{
${ }^{21}$ VILANOVA, Lourival. Causalidade e Relação no Direito. 4 ed. São Paulo: RT, 2000, p. 141.

${ }^{22}$ ALEXY, Robert. Teoria da argumentação jurídica: a teoria do discurso racional como teoria da justificação jurídica. São Paulo, Landy, 2001, p. 247.

${ }^{23}$ STAUB, Hermann. Die positiven Vertragsverletzungen. 2 ed. Berlim, 1913.

${ }^{24}$ ALEXY, Robert. Teoria da argumentação jurídica: a teoria do discurso racional como teoria da justificação jurídica. São Paulo, Landy, 2001, p. 248.
}

: a teoria do discurso racional como teoria da 
por conta de outros princípios ${ }^{25} \%$. Contudo, ao invés de serem utilizados como proposições normativas, podem ser introduzidos como descrições de estados de coisas em que são considerados bons.

Ressalte-se que a utilização de proposições dogmáticas na justificação de outras proposições dogmáticas é possível. Entretanto, estas também necessitariam ser justificadas, e assim por diante. Em algum ponto, as proposições dogmáticas se esgotariam e seriam necessários outros argumentos. Como as proposições dogmáticas têm conteúdo normativo esses outros argumentos só poderiam ser argumentos práticos gerais. Isto demonstra que nenhum tipo de proposição é suficiente por si mesmo.

Neste passo, é alvissareiro traçar uma distinção entre a justificação e o exame de

\footnotetext{
${ }^{25}$ ALEXY, Robert. Teoria da argumentação jurídica justificação jurídica. São Paulo, Landy, 2001, p.
} 248. 


\section{Quaestio Iuris}

vol.05, $\mathrm{n}^{\mathrm{o}} 01$. ISSN 1516-0351

proposições dogmáticas. "A justificação ocorre quando uma proposição é derivada de outras proposições; o exame ocorre quando se pergunta se as proposições deriváveis de uma proposição por si mesma, ou juntamente com outras proposições são aceitáveis ${ }^{26 "}$. Não se pode perder de vista, todavia, que ambos, o exame e a justificação de proposições dogmáticas, conduzem às proposições gerais práticas, uma vez que, como já mencionado, as proposições que são utilizadas na refutação de proposições dogmáticas não podem sempre ser proposições dogmáticas, ou seja, proposições de mesma espécie.

Deste modo, a aceitabilidade de uma proposição dogmática está condicionada ao atendimento dos requisitos do exame sistemático no sentido mais estrito, já que a proposição sob escrutínio deve se amoldar sem contradições na classe das proposições já aceitas e das normas jurídicas válidas ${ }^{27}$.

Entretanto, atender aos requisitos do exame sistemático no sentido mais estrito consiste tão somente em uma condição necessária, porém não suficiente, para a aceitabilidade de uma proposição dogmática. Toda proposição dogmática tem de ser justificada com o recurso de ao menos um argumento prático geral sempre que estiver sujeita à dúvida. Deve, pois, suportar também um exame sistemático no sentido mais amplo.

A dogmática jurídica é, portanto, uma atividade racional e, apesar de não descartar o discurso prático geral, consiste em um instrumento que pode acarretar resultados inatingíveis unicamente pelo emprego do discurso prático geral.

A dogmática assume, desta forma, as seguintes funções:

a) função de estabilização, que é realizada pelo reconhecimento de que soluções particulares para questões práticas podem ser retidas e assim reproduzidas quando

\footnotetext{
${ }^{26}$ ALEXY, Robert. Teoria da argumentação jurídica: a teoria do discurso racional como teoria da justificação jurídica. São Paulo, Landy, 2001, p. 250.

27 “Toda proposição que tem conteúdo normativo é candidata à justificação por meio de proposições práticas gerais. A característica especial das proposições dogmáticas consiste no fato de que elas podem ser sistematicamente examinadas. Dois modos de exame sistemático podem ser distinguidos. O primeiro se refere às relações lógicas entre as proposições a serem examinadas e as proposições dogmáticas remanescentes, bem como às formulações de normas jurídicas pressupostamente válidas (exame sistemático no sentido mais estrito). $\mathrm{O}$ segundo modo se refere ao relacionamento a ser julgado do ponto de vista prático geral daquelas proposições normativas singulares que são justificáveis com a ajuda de proposições dogmáticas que estão sendo examinadas, as proposições normativas singulares justificáveis com a ajuda das proposições dogmáticas remanescentes e a formulação de normas legais respectivamente (exame sistemático no sentido mais amplo)". ALEXY, Robert. Teoria da argumentação jurídica: a teoria do discurso racional como teoria da justificação jurídica. São Paulo, Landy, 2001, p. 250.
} 


\section{Quaestio Iuris}

vol.05, $\mathrm{n}^{\circ} 01$. ISSN $1516-0351$

requerido com a ajuda das proposições dogmáticas. Isto confere expressão ao princípio da universalizabilidade e ao princípio da justiça, inadmitindo-se o abandono de uma proposição dogmática sem qualquer razão. Isto, por outro lado, não significa que uma vez aceita uma proposição dogmática, esta precisa ser estritamente retida por um período ilimitado, mas apenas que a razão para a nova solução deve ser forte o suficiente para justificar não só a nova solução, mas também o rompimento da tradição. O tema será adiante melhor debatido quando da análise da aplicação do precedente na argumentação jurídica e da possibilidade de distinguir e a de prevalecer;

b) função de desenvolvimento, já que a institucionalização da dogmática, envolvendo a expansão da discussão jurídica quanto a tempo, tópicos e pessoas, torna possível diferenciar as proposições dogmáticas com um grau consideravelmente maior, e desenvolver modos de examiná-las tais como não seriam possíveis em discussões $a d$ hoc. Isso torna possível algo como um progresso de desenvolvimento na dogmática;

c) função redutora de encargo, pois a justificação dogmática pode adotar, ao menos provisoriamente, itens que foram previamente examinados e aceitos. Isto reduz o encargo do processo justificativo, a ponto de, na ausência de alguns motivos especiais, novo exame ser desnecessário. Por outro lado, há situações em que é necessário fazer uma escolha entre princípios alternativos da dogmática, chegando à decisão em um caso individual, e essa escolha, evidentemente, deve ser justificada. Deste modo, há de se reconhecer que a dogmática pode não só ter o efeito de reduzir o encargo, mas também de agravá-lo;

d) função técnica, uma vez que a dogmática exerce também uma função informativa, melhorando o "ensino" e a "aprendizagem" da lei e, assim, pelo mesmo critério o seu aperfeiçoamento a ser estabelecido;

e) função controladora, que decorre do fato de o estudo da dogmática jurídica facilitar a decisão dos casos não como instâncias isoladas, mas considerados à luz de toda uma linha de casos já decididos e ainda por decidir. A exemplo da função de estabilização, confere expressão ao princípio da universalizabilidade e ao princípio da justiça;

f) função heurística, já que a dogmática contém um grande alcance de modelos para resolver problemas, distinções e pontos de vista, que não ocorreriam prontamente a alguém começar sempre de novo. Mesmo que isso não bastasse para determinar uma decisão, ainda é uma ajuda real usar esse aparato. Desta forma, 
um sistema de dogmática jurídica pode ser 'um fecundo ponto de partida para fazer novas descobertas e conexões, visto que, na mesma extensão em que concentra e melhora a fertilidade de nosso estágio de entendimento, adquirido com respeito a certos problemas, se torna um estimulante para novas descobertas que não viriam à mente, muito menos adquiririam solidez se a reflexão fosse confinada a pontos individuais em vez de ter um caráter sistemático, ${ }^{28}$.

Constata-se, pois, com clareza, que a dogmática jurídica é um instrumento que pode acarretar resultados inatingíveis apenas pelo recurso ao discurso prático geral e que consiste eminentemente em uma atividade racional.

Percebe-se ainda que uma teoria da argumentação jurídica deve necessariamente levar em conta a regra dos precedentes, mesmo quando se tratar de um sistema de "civil law", ou, como prefere Alexy, mesmo no âmbito da lei continental européia ${ }^{29}$. A razão de tal assertiva reside no princípio da universalizabilidade, isto é, na exigência de que casos iguais sejam tratados do mesmo modo, o que repousa também na justiça como qualidade formal, conforme já se buscou demonstrar. Ocorre que raramente dois casos são, de fato, idênticos. Na verdade, sempre se pode apontar alguma diferença. O problema consiste, pois, em definir que diferenças são relevantes. Surge, deste modo, a possibilidade de se exigir respeito pelo precedente como uma questão de princípio, embora se admita exceções sujeitas à imposição do argumento do encargo sobre qualquer um que se proponha fazer uma exceção ${ }^{30}$. Aqui o princípio da inércia, tal e qual formulado por Perelman, é considerado adequado com a exigência de que uma decisão só pode ser alterada se boas razões suficientes puderem ser aduzidas para se fazer isso ${ }^{3132}$.

Daí emerge a possibilidade de distinguir e a de prevalecer.

A técnica de distinguir é usada onde a norma a ser observada do ponto de vista casual é entendida tão estritamente - por exemplo, através da

\footnotetext{
${ }^{28}$ ALEXY, Robert. Teoria da argumentação jurídica: a teoria do discurso racional como teoria da justificação jurídica. São Paulo, Landy, 2001, p. 257.

29 “Atualmente, mesmo na lei continental européia, a importância - ao menos a importância de facto dos precedentes é reconhecida por todos os lados. O que é disputado é sua posição teórica. A disputa se concentra acima de tudo na questão de se pelo precedente deve ser acordado o caráter de uma fonte de lei”. ALEXY, Robert. Teoria da argumentação jurídica: a teoria do discurso racional como teoria da justificação jurídica. São Paulo, Landy, 2001, p. 258.

${ }^{30}$ ALEXY, Robert. Teoria da argumentação jurídica: a teoria do discurso racional como teoria da justificação jurídica. São Paulo, Landy, 2001, p. 259.

${ }^{31}$ PERELMAN, Chaïm e OLBRECHTS-TYTECA, Lucie. La nouvelle rhétorique: Traité de l'argumentacion. Paris, 1958. 2 ed. Inalterada Brüssel, 1970.

${ }^{32}$ ALEXY, Robert. Teoria da argumentação jurídica: a teoria do discurso racional como teoria da justificação jurídica. São Paulo, Landy, 2001, p. 262.
} 
introdução de uma característica não presente nos fatos do caso - que ela não mais se aplica. Neste processo vale a pena continuar considerando o precedente como tal. Ao contrário, a técnica de prevalecer consiste na rejeição do precedente. Aqui, só um ponto de interesse: tanto a distinção quanto o prevalecimento requerem justificação

\section{$\underline{\text { III - Críticas à argumentação jurídica na obra de Robert Alexy }}$}

Conforme já salientado, para Alexy, a teoria do discurso tem um caráter procedimental. Desta forma, uma norma é correta quando o resultado do processo pode ser definido pelas regras do discurso. Contudo, surgem críticas relacionadas a esse conceito procedimental da exatidão prática.

Segundo Weinberger os discursos podem ser um meio para 'desenvolver o pensamento e fazê-lo dar frutos', mas a correção dos resultados não pode ser garantida pelas regras do discurso. Não há 'nenhum caminho da opinião dos participantes do discurso para a verdade ou correção objetivas ${ }^{, 33}$.

A tese de Weinberger de que a teoria do discurso não assegura boas idéias e bons julgamentos só pode ser considerada correta se a interpretarmos de forma tão rígida que uma pressuposição não aceitável se torne evidente. Nesta linha, seria possível afirmar que do fato de se cumprir as regras do discurso, juntamente com outras premissas, além da capacidade suficiente de descobrir e de julgar dos participantes do discurso, não emergiria, necessariamente, a correção absoluta dos resultados.

Insta mencionar que a teoria do discurso desenvolvida por Robert Alexy ancorase na constatação de que um discurso só é totalmente racional quando cada participante do discurso é racional. Deste modo, em virtude do mau uso ou uso falho que os participantes façam da capacidade de descobrir e julgar, podem surgir equívocos. Contudo, revela-se verdadeiro absurdo, sobretudo no que se refere às questões práticas, exigir a certeza da correção absoluta, uma vez que nenhum procedimento pode assegurar isto.

De fato, não é possível aceitar que exista uma única resposta possível para cada pergunta prática. Aqueles que defendem tal posição separam o conceito de correção dos conceitos de justificação e comprovação. Daí só pode surgir um conceito absoluto de

\footnotetext{
${ }^{33}$ ALEXY, Robert. Teoria da argumentação jurídica: a teoria do discurso racional como teoria da justificação jurídica. São Paulo, Landy, 2001, p. 302.
} 
correção, que tem um caráter não-procedimental. A partir da relação que se estabelece entre correção e discurso real, constata-se a possibilidade de ter-se uma relativização do conceito de correção, que se relaciona com as regras do discurso, com a medida de sua realização, com os participantes e com a duração do discurso. Assim sendo, deve-se eliminar a exigência desarrazoada de uma certeza da correção absoluta, o que deixa evidente "que nenhum procedimento é melhor do que o discurso, para desenvolver e ao mesmo tempo controlar racionalmente a capacidade de descobrir e de julgar, e, dessa maneira, aproximar-se mais da correção ${ }^{34,}$.

Para Alexy, cada discurso de aplicação contém obrigatoriamente um discurso de fundamentação, o que é conseqüência da adoção de uma práxis decisória universalista. Abdicar disso, significaria renunciar à mais importante exigência da racionalidade prática $^{35}$.

Reitera o autor a importância de que os interessados argumentem de forma racional ou, pelo menos, "finjam" que seus argumentos são formados de tal forma que se encontram nas condições ideais para obter o acordo de todos. Esta seria a razão para que a argumentação jurídica figurasse como caso especial do discurso prático. Sobre a formação da decisão judicial, salienta ainda que:

\section{Quando o juiz deixa as partes falarem, porém não participa da brincadeira, na medida em que no final decide de forma a fazer valer o direito como ele o entende, ele trata as partes como pessoas que não entenderam o que é um processo jurídico, e que, portanto, não podem participar dele. Isso mostra que a argumentação em juízo não só deve ser interpretada no sentido de uma teoria do discurso, mas também precisa ser interpretada dessa maneira ${ }^{36}$.}

Neste particular, Manuel Atienza afirma que, por outro lado, a argumentação não pode gerar uma aceitação acrítica do direito, não pode fazer com que os futuros juristas tenham uma visão puramente instrumental do direito que, ao final, conduza à idéia de que tudo que é tecnicamente possível é também eticamente possível. Trata-se, pois, da adoção de uma "concepção material" da argumentação, segundo a qual o

\footnotetext{
${ }^{34}$ ALEXY, Robert. Teoria da argumentação jurídica: a teoria do discurso racional como teoria da justificação jurídica. São Paulo, Landy, 2001, p. 304.

${ }^{35}$ FERREIRA, Fernando Galvão de Andréa. "O discurso jurídico como discurso prático: aspectos do debate entre Robert Alexy e Jürgen Habermas". In: Revista da Faculdade de Direito de Campos, ano VII, $\mathrm{n}^{\circ} 9$ - dezembro de 2006, p. 96.

${ }^{36}$ ALEXY, Robert. Teoria da argumentação jurídica: a teoria do discurso racional como teoria da justificação jurídica. São Paulo, Landy, 2001, p. 324.
} 
trabalho do jurista consiste em uma técnica artesanal, cuja "justificação" se coloca mais em relação ao produto, a sua eficácia, do que em relação à "correção" dos meios empregados ${ }^{37}$.

\title{
$\underline{\text { IV - Ponderação e representação argumentativa }}$
}

Um dos principais temas no atual debate sobre a interpretação de direitos fundamentais reside na ponderação, uma vez que ela assume um papel central na prática de muitos tribunais constitucionais.

No Direito Constitucional alemão a ponderação é parte de um princípio mais amplo: o princípio da proporcionalidade.

O princípio da proporcionalidade, por sua vez, se conforma a partir de outros três (sub)princípios: adequação, necessidade e proporcionalidade em sentido estrito. Estes princípios expressam a idéia de otimização.

Fernando Galvão de Andréa Ferreira afirma que a noção de mandamentos de otimização

\begin{abstract}
conduz, em verdade, à inclusão, no âmbito do Direito, de critérios oriundos da área da racionalidade econômica, e que correspondem ao princípio da proporcionalidade (Verhältnismässigkeit) do direito constitucional alemão, o qual diz que uma intervenção em um direito fundamental somente é permitida, se atendidos três requisitos: $1^{o}$ ) ela deve ser apropriada (geeignet) a se alcançar o objetivo (Ziel); $2^{\circ}$ ) deve, além disso, ser necessária (erfordelich), isto é, não deve existir nenhum outro meio mais suave, ou menos gravoso (weniger eingreifendes Mittel); $3^{\circ}$ ) tem que ser proporcional, isto é, os fundamentos justificadores da intervenção devem ter peso tanto maior, quanto maior for a intervenção ${ }^{38}$.
\end{abstract}

Neste passo, interpretar os direitos fundamentais de acordo com o princípio da proporcionalidade é tratá-los como mandamentos (requisitos) de otimização, isto é, como princípios e não simplesmente como regras. Reitere-se que os princípios, como mandamentos de otimização, são normas que requerem que algo se realize com a maior amplitude possível dentro das possibilidades jurídicas e fáticas.

A ponderação não é mais que a otimização relativa a princípios contrapostos. Portanto, o terceiro subprincípio, o da proporcionalidade em sentido estrito, pode ser

\footnotetext{
${ }^{37}$ ATIENZA, Manuel. "El derecho como argumentación”. In: ATIENZA, Manuel \& FERRAJOLI, Luigi. Jurisdicción y argumentación en el Estado constitucional de derecho. São Paulo: Landy, 2000, p. 43.

${ }^{38}$ FERREIRA, Fernando Galvão de Andréa. "O discurso jurídico como discurso prático: aspectos do debate entre Robert Alexy e Jürgen Habermas". In: Revista da Faculdade de Direito de Campos, ano VII, $\mathrm{n}^{\circ} 9$ - dezembro de 2006, p. 95.
} 


\section{Quaestio Iuris}

vol.05, $\mathrm{n}^{\mathrm{o}} 01$. ISSN 1516-0351

expresso pela seguinte regra: quanto maior for o grau de insatisfação ou de detrimento de um direito ou princípio, maior deve ser a importância de satisfazer o outro. Esta regra poderia ser denominada "lei da ponderação"39.

O fenômeno da ponderação dentro do Direito Constitucional gera uma grande quantidade de problemas, porém duas objeções se fazem mais relevantes. A primeira rechaça a idéia de que a ponderação seja um procedimento racional. Tratar-se-ia de uma figura retórica que permitiria níveis de subjetividade ilimitados. A razão desta objeção é, como sustenta Hebermas, que "não existem standards racionais" para ponderar ${ }^{40}$. A segunda objeção se refere a um problema conceitual e, neste aspecto, pode-se, mais uma vez, aludir a Habermas. Segundo o autor, o recurso à ponderação deixa a regulação jurídica fora da esfera definida por conceitos como bom e mau, correto e incorreto, assim como a posiciona fora da idéia de justificação, colocando-a dentro de uma esfera definida por conceitos como adequado e inadequado e como discricionariedade. Na esteira desta crítica, percebe-se que

La decisión de um tribunal es en si misma um juicio de valor que refleja, de manera más o menos adecuada, una forma de vida que se articula en el marco de un ordem de valores concreto. Pero este juicio ya no se relaciona con las alternativas de una decisión correcta o incorrecta ${ }^{41}$.

Contudo, caso a ponderação fosse excluída da esfera da objetividade, sofreria um duro golpe, uma vez que está conectada necessariamente com uma pretensão de correção.

Para melhor compreendê-la é necessário, preliminarmente, proceder a um estudo da estrutura da ponderação. A "lei de ponderação" pode ser fragmentada em três etapas:

$\left.1^{a}\right)$ estabelece os graus de insatisfação ou detrimento de um primeiro princípio;

$2^{a}$ ) estabelece a importância de satisfazer o princípio oposto;

$3^{\mathrm{a}}$ ) estabelece se a necessidade de satisfazer o segundo princípio realmente justifica adotar postura em detrimento do primeiro.

Esta estrutura, por si só, não é, todavia, suficiente para demonstrar que a ponderação é racional. Para se atingir tal pretensão, faz-se necessário reconhecer que na

${ }^{39}$ ALEXY, Robert. "Ponderación, control de constitucionalidad y representación”. In: ANDRÉS IBAÑEZ, Perfecto \& ALEXY, Robert. Jueces y ponderación argumentativa. México: Universidad Nacional Autônoma de México - UNAM, 2006, p. 02.

${ }^{40}$ HABERMAS, Jürgen. Between Facts and Norms: contributions to a discourse theory of law and democracy. Tradução de William Rehg. Cambrigde: MIT, 1996, p. 256.

${ }^{41}$ HABERMAS, Jürgen. "Reply to Symposium Participants". In: ROSENFELD, Michel e ARATO, Andrew (eds.). Habermas on Law and Democracy. Los Angeles e Londres: Berkeley, 1998, p. 430. 
ponderação está presente, ainda que de forma implícita, um sistema de inferências, que, por sua vez, está intrinsecamente conectado ao conceito de correção. Em um sistema de inferências, a subsunção a uma regra pode expressar-se mediante um esquema dedutivo de "justificação interna", que se constrói também com auxílio da lógica da proporcionalidade.

É de central importância para a teoria do discurso jurídico que, no caso da ponderação de princípios, exista este esquema dedutivo, que Alexy denomina de "fórmula do peso" e a representa do seguinte modo: $\mathrm{Wi}, \mathrm{j}=\mathrm{Ii} / \mathrm{Ij}{ }^{42}$.

Nesta fórmula, Ii representa a intensidade da interferência com o princípio Pi e Ij representa a importância de satisfazer o princípio em colisão, $\mathrm{Pj}$. Wi,j equivale, deste modo, ao peso concreto de Pi. Esta fórmula evidencia, pois, que o peso concreto de um princípio é, na realidade, um peso relativo.

Outra objeção pode ser aqui apontada: a de que só se pode falar de cocientes na presença de números e os "exercícios" de ponderação levados a cabo no âmbito do Direito Constitucional não se utilizam de números. Contudo, como esclarece Alexy, há várias maneiras de se atribuir valores aos cocientes indicados. Uma delas seria valer-se de uma seqüência geométrica $2^{\circ}, 2^{1}$ e $2^{2}$, isto é, dos valores 1,2 e 4 , conforme se tivesse uma interferência leve, moderada e grave de um princípio em relação ao outro que com ele está em colisão ${ }^{43}$.

De qualquer modo, o que não se pode perder de vista é que:

La racionalidad de una estructura inferencial depende, esencialmente, de si conecta premisas que, a su vez, puedan ser justificadas racionalmente. La estructura que expresa la fórmula del peso no sería uma estructura racional si su input fuesen premisas que la expulsaran del ámbito de la racionalidad. No es esse, sin embargo, el caso. El input que representan los números son juicios. Um ejemplo de ello es el juicio de que la descripción pública de una persona minusválida como "tullido" supone uma "vulneración grave" de su derecho a la personalidad. Este juicio expresa una pretensión de corrección que, dentro del discurso, puede ser justificada como la conclusión de otro esquema de inferencia. El Tribunal Constitucional Federal opero de esta forma presentando el argumento de que la descripción de um parapléjico como "tullido" era humillante e irrespetuosa. Junto con la corrección de los argumentos relativos a la intensidad de la interferencia con la libertat de expresión, la fórmula del peso trasfiere la correción de este argumento al

\footnotetext{
${ }^{42}$ ALEXY, Robert. "Ponderación, control de constitucionalidad y representación”. In: ANDRÉS IBAÑEZ, Perfecto \& ALEXY, Robert. Jueces y ponderación argumentativa. México: Universidad Nacional Autônoma de México - UNAM, 2006, p. 07.

${ }^{43}$ ALEXY, Robert. "Ponderación, control de constitucionalidad y representación". In: ANDRÉS IBAÑEZ, Perfecto \& ALEXY, Robert. Jueces y ponderación argumentativa. México: Universidad Nacional Autônoma de México - UNAM, 2006, p. 08.
} 
juicio sobre el derecho de Titanic en el caso concreto; lo cual una vez más, implica al juicio que expresa la decisión del Tribunal - acompañado de las premisas adicionales - . Esta es la estructura racional para establecer la corrección de los juicios jurídicos dentro de un discurso. Los elementos básicos de esta estructura son juicios o proposiciones ${ }^{44}$.

As decisões ou proposições conectadas pela fórmula do peso devem ser justificadas mediante ulteriores argumentos. Em outras palavras, a fórmula do peso é uma espécie de argumento. As diversas formas de argumento definem a estrutura lógica de movimentos dentro do discurso como estes movimentos se relacionam entre si.

O discurso, ao seu turno, é um dos elementos do constitucionalismo discursivo e a ponderação está conectada com o discurso. A ponderação não é possível sem o discurso e as distintas espécies de argumento ou estruturas de inferência incluem necessariamente a estrutura ponderativa, tal como o manifesta a fórmula do peso.

A ponderação não somente está relacionada necessariamente com o discurso como também com os direitos fundamentais. Daí segue que os direitos fundamentais estão necessariamente relacionados com o discurso.

Deve-se salientar que a ponderação não conduz a decisões particulares, na medida em que, sobre a decisão de ponderação, sempre é possível a formulação de uma regra, permitindo, assim, o estabelecimento de uma ponte entre a ponderação do caso particular e a universalização (universalizabilidade) ${ }^{45}$.

Nesta altura, insere Alexy as discussões acerca do controle de constitucionalidade. Para o autor, o controle de constitucionalidade consiste na expressão de superioridade ou prioridade dos direitos fundamentais frente à legislação infra-constitucional (parlamentar). A declaração de inconstitucionalidade de uma lei implica na contradição de, pelo menos, uma norma constitucional. Este controle, realizado sobre atos do legislador, tem um caráter proposicional e discursivo,

\footnotetext{
${ }^{44}$ ALEXY, Robert. "Ponderación, control de constitucionalidad y representación”. In: ANDRÉS IBAÑEZ, Perfecto \& ALEXY, Robert. Jueces y ponderación argumentativa. México: Universidad Nacional Autônoma de México - UNAM, 2006, pp. 09-10.

${ }^{45}$ FERREIRA, Fernando Galvão de Andréa. "O discurso jurídico como discurso prático: aspectos do debate entre Robert Alexy e Jürgen Habermas". In: Revista da Faculdade de Direito de Campos, ano VII, $\mathrm{n}^{\circ} 9$ - dezembro de 2006, p. 96. "Nesse sentido, é possível afirmar que sempre que um princípio for, em última análise, uma razão decisiva para um juízo concreto de dever-ser, então, esse princípio é o fundamento de uma regra, que representa uma razão definitiva para esse juízo concreto". ALEXY, Robert. Teoria dos direitos fundamentais. Tradução de Virgílio Afonso da Silva. São Paulo: Malheiros, 2008, p. 108. 51

BARROSO, Luís Roberto. O Controle de Constitucionalidade no Direito Brasileiro. 2 ed. São Paulo: Saraiva, 2006, p. 02.
} 


\section{Quaestio Iuris}

vol.05, $\mathrm{n}^{\mathrm{o}} 01$. ISSN 1516-0351

constituindo a questão da ponderação o principal problema da dimensão metodológica do controle de constitucionalidade.

Mais do que isso, este controle representa um exercício da autoridade estatal e, em um Estado Democrático em que todo poder emana do povo, só se legitima caso se compatibilize com a democracia. Assim surge a indagação sobre como compatibilizar o controle de constitucionalidade com um sistema em que a idéia de representação parece estar necessariamente associada às eleições. Trata-se da tão comentada dificuldade contramajoritária.

Em uníssono com o que se acaba de afirmar, salienta Luís Roberto Barroso que:

Um dos fundamentos do controle de constitucionalidade é a proteção dos direitos fundamentais, inclusive e sobretudo os das minorias, em face de maiorias parlamentares eventuais. Seu pressuposto é a existência de valores materiais compartilhados pela sociedade que devem ser preservados de injunções estritamente políticas. A questão da legitimidade democrática do controle judicial é um dos temas que têm atraído mais intensamente a 51 reflexão de juristas, cientistas políticos e filósofos da Constituição [...] (Grifei).

Para Alexy, a única maneira de reconciliar o controle de constitucionalidade com a democracia é considerar que aquele também é uma forma de representação do povo. Para cumprir tal desiderato, é essencial a idéia de representação argumentativa, uma vez que, na concepção do referido autor, um modelo democrático adequado deve incluir não apenas a decisão (eleições), mas também a argumentação.

$\mathrm{Na}$ argumentação constitucional é possível, em boa medida, implementar uma argumentação racional e, portanto, dotada de objetividade. Além disso, ao incluir a idéia de argumentação no contexto da democracia, e democracia se torna, de fato, deliberativa. Um sistema de tomada de decisões centrado nos conceitos de eleições de regra da maioria caracterizaria um modelo de democracia puramente decisionista.

La democracia deliberativa es un esfuerzo para institucionalizar el discurso como médio para la toma pública de decisiones, tanto como sea posible. Por esta misma razón, la ralación entre el pueblo y el parlamento no debe estar únicamente determinada por las decisiones expresadas a través de las elecciones y los votos sino, también, mediante argumentos. En este sentido, la representación parlamentaria del pueblo es, a la vez, volitiva o decisionista y argumentativa o discursiva.

En cambio, la representación del pueblo en el tribunal constitucional es puramente argumentativa. El hecho de que la representación parlamentaria 
sea al mismo tiempo volitiva y discursiva demuestra que la argumentación y la representación no son incompatibles. ${ }^{46}$.

À luz da fórmula do peso, a existência de casos em que os argumentos levem a um empate não supõe perigo algum para o controle de constitucionalidade. Nesses casos, o legislador tem discricionariedade e a constituição não deve disciplinar toda e qualquer situação. De fato, o que se reclama é a existência de hipóteses com amplo alcance, em que as valorações sobre a intensidade de interferência de um princípio (ou direito fundamental) em outro possa ser respaldada por argumentos reconhecidos como bons ou, pelo menos, plausíveis; argumentos que, ademais, sejam aceitos constitucionalmente.

Contudo, além da plausibilidade dos argumentos, é necessário que os tribunais sustentem que tais argumentos são argumentos do povo, senão que, pelo menos, um número suficiente de pessoas aceite, a longo prazo, estes argumentos como razões de correção.

Somente as pessoas racionais são capazes de aceitar argumentos com base em sua correção ou sensatez. Isto mostra que existem duas condições fundamentais para a verdadeira representação argumentativa:

a) a existência de argumentos corretos ou razoáveis;

b) a existência de pessoas racionais que estão dispostas e são capazes de aceitar argumentos corretos e razoáveis simplesmente por serem corretos ou razoáveis.

Deste modo, o controle de constitucionalidade somente pode ter êxito se os argumentos apresentados pelo tribunal constitucional são razoáveis e se um número suficiente de membros da comunidade é capaz de exercitar suas capacidades racionais e deseja realmente fazê-lo.

\section{$\underline{\mathrm{V}}-$ Conclusão}

Diante do exposto, insta salientar, mais uma vez, o relevo que tem adquirido a argumentação jurídica no estudo e aplicação do Direito. Consiste, como se demonstrou, em um caso especial da argumentação prática geral e permite afirmar que:

\footnotetext{
${ }^{46}$ ALEXY, Robert. "Ponderación, control de constitucionalidad y representación”. In: ANDRÉS IBAÑEZ, Perfecto \& ALEXY, Robert. Jueces y ponderación argumentativa. México: Universidad Nacional Autônoma de México - UNAM, 2006, p. 14.
} 
A ciência jurídica dogmática pode ser entendida como uma institucionalização do discurso prático condicionada à existência de uma ordem jurídica. Essa institucionalização torna possível obter resultados que não seriam possíveis usando-se unicamente os métodos do discurso prático geral. A discussão se amplia consideravelmente com respeito a tempo, pessoas e tópicos. Desta maneira, tanto a consistência quanto a diferenciação da tomada de decisão podem ser aumentadas. A primeira é requerida diretamente por princípios de não-contradição, universalisabilidade, e inércia, a última indiretamente pelas regras de racionalidade exigência de abertura e consideração de todos os argumentos. Satisfazer essas exigências corresponde às funções estabilizadoras, de desenvolvimento, controladoras, e heurísticas, executadas pela dogmática jurídica $^{47}$.

Tal procedimento argumentativo está pautado na idéia de correção e, na perspectiva de Alexy, não conduz a decisões particulares, uma vez que, sobre a decisão sempre é possível a formulação de uma regra, permitindo, desta forma, o

estabelecimento de uma ponte entre a ponderação do caso particular e a universalização. As valorações não implicam, portanto, na existência de um campo livre, de puro arbítrio por parte daquele que deve decidir o caso, reclamando que sejam as decisões tomadas de forma objetiva. Reconhece, por outro lado, o autor que "nenhum procedimento que garanta certeza está à vista ainda. [Entretanto] Qualquer pessoa que equipare racionalidade com certeza terá de renunciar à idéia de uma teoria da argumentação jurídica racional" ${ }^{48}$.

Neste esteira, é inquestionável que existem limites na argumentação jurídica e disto só de afastaria caso

se pudesse partir da premissa de que a decisão de todos os casos de um sistema jurídico fosse estritamente estabelecida pelas leis válidas, de modo que cada caso pudesse ser solucionado através de uma simples subsumtion. Então não se trataria mais da questão de se as leis são justas ou injustas. Em ambos os casos não haveria espaço para um discurso jurídico. Esta premissa é tudo menos aceitável. Todo sistema jurídico contém espaços que podem ser preenchidos com discursos jurídicos ${ }^{49}$.

Mais do que isso, conforme já mencionado, associar a argumentação jurídica a um ensino mais "prático" do Direito não pode culminar na aceitação acrítica do Direito,

\footnotetext{
${ }^{47}$ ALEXY, Robert. Teoria da argumentação jurídica: a teoria do discurso racional como teoria da justificação jurídica. São Paulo, Landy, 2001, p. 270.

${ }^{48}$ ALEXY, Robert. Teoria da argumentação jurídica: a teoria do discurso racional como teoria da justificação jurídica. São Paulo, Landy, 2001, p. 272.

${ }^{49}$ ALEXY, Robert. Teoria da argumentação jurídica: a teoria do discurso racional como teoria da justificação jurídica. São Paulo, Landy, 2001, p. 322.
} 
isto é, gerar entre os futuros juristas uma visão puramente instrumental do Direito, que leve à aceitação de tudo aquilo que é tecnicamente possível como ético.

\begin{abstract}
Pues bien, yo diria que todo eso es, en cierto modo, una consecuencia de haver desarrollado un modelo - una concepción - de la argumentación jurídica que potencia casi exclusivamente los elementos de tipo retórico, em detrimento de lo que luego llamaré elementos formales y materiales de la argumentación: el aspecto más estrictamente lógico y la justificación en sentido estricto de las decisiones ${ }^{50}$.
\end{abstract}

Isto apenas reflete a preocupação manifestada também por Alexy no sentido de exigir, além da existência de uma lógica interna (justificação interna), uma preocupação com a validade das premissas usadas na justificação (justificação externa) no âmbito do discurso jurídico. Surge aqui a noção de que a "razão jurídica" não é apenas uma razão de caráter instrumental, estando orientada não apenas pelos meios, mas também à consecução de determinados fins, ou seja, está atrelada à noção de correção ${ }^{51}$.

Cumpre ainda mencionar que, na comparação entre diferentes culturas jurídicas, é muito mais fácil encontrar nos Estados Unidos (país de "common law”) do que na Europa (países de "civil law”) uma concepção do Direito como razão. Isto porque, nos países de base romano-germânica, tem muita força a visão do Direito como um conjunto de regras preexistentes.

Por outro lado, dentro de los sistemas de common law, el derecho norteamericano parece ser más sustantivista (más abierto, al aceptar como "proposiciones del derecho" - fuentes - critérios no baseados en la autoridad) y el inglés más formalista (com un sistema de fuentes más inmediatamente ligado a las autoridades $)^{52}$.

Há, deste modo, uma separação entre o positivismo normativista e a visão do Direito como argumentação. Se os normativistas vêem o Direito como uma realidade previamente definida, como um conjunto de normas, um livro, um edifício ou uma cidade que existe para ser contemplada e descrita, aqueles que vislumbram o Direito como argumentação consideram que se trata mais de uma atividade, de uma prática complexa, a imagem mais adequada seria a de uma empresa, de uma obra em que se participa. Os juristas são, sob esta ótica, partícipes de uma tarefa comum de escrever

\footnotetext{
${ }^{50}$ ATIENZA, Manuel. "El derecho como argumentación”. In: ATIENZA, Manuel \& FERRAJOLI, Luigi. Jurisdicción y argumentación en el Estado constitucional de derecho. São Paulo: Landy, 2000, pp. 13-14. ${ }^{51}$ ATIENZA, Manuel. "El derecho como argumentación”. In: ATIENZA, Manuel \& FERRAJOLI, Luigi. Jurisdicción y argumentación en el Estado constitucional de derecho. São Paulo: Landy, 2000, p. 73.

${ }^{52}$ ATIENZA, Manuel. "El derecho como argumentación”. In: ATIENZA, Manuel \& FERRAJOLI, Luigi. Jurisdicción y argumentación en el Estado constitucional de derecho. São Paulo: Landy, 2000, p. 21.
} 


\section{Quaestio Iuris}

vol.05, $\mathrm{n}^{\circ}$ 01. ISSN 1516-0351

uma novela em cadeia, da construção de uma catedral ou ainda da atividade de construir e melhorar uma cidade em que todos têm que viver ${ }^{53}$.

No que tange à interpretação dos direitos fundamentais insta relembrar que considerá-los à luz do princípio da proporcionalidade significa tratá-los como mandamentos (requisitos) de otimização, isto é, como princípios e não simplesmente como regras, já que demandarão que algo se realize com a maior amplitude possível dentro das possibilidades jurídicas e fáticas. Também nesta seara adquire importância o estudo da argumentação jurídica, pois as decisões ou proposições conectadas pela fórmula do peso, proposta por Alexy, devem ser justificadas mediante ulteriores argumentos. Em outras palavras, a fórmula do peso é uma espécie de argumento que integra o discurso e o discurso, ao seu turno, é um dos elementos do "Estado constitucional", para utilizar a expressão de Manuel Atienza. Daí falar-se em uma representatividade argumentativa como apta a legitimar o próprio controle de constitucionalidade das leis, atos administrativos e decisões judiciais ${ }^{54}$.

Por fim, é alvissareiro reiterar que, por esta ótica, o Direito é vislumbrado como um processo, integrado por fases, momentos ou aspectos da atividade, da prática social em que consiste o próprio Direito. Isto é, trata-se de reconhecer que o Direito é uma realidade dinâmica e que, portanto, consiste não apenas em uma série de normas ou de enunciados, mas também em uma prática social complexa que inclui, além das normas, procedimentos, valores, ações etc ${ }^{61}$, mesmo em se tratando de um sistema de base romano-germânica.

\section{VI - Referências}

ALEXY, Robert. Teoria da argumentação jurídica: a teoria do discurso racional como teoria da justificação jurídica. São Paulo, Landy, 2001.

\footnotetext{
${ }^{53}$ ATIENZA, Manuel. “El derecho como argumentación”. In: ATIENZA, Manuel \& FERRAJOLI, Luigi. Jurisdicción y argumentación en el Estado constitucional de derecho. São Paulo: Landy, 2000, pp. 36-37.

${ }^{54}$ BARROSO, Luís Roberto. O Controle de Constitucionalidade no Direito Brasileiro. 2 ed. São Paulo: Saraiva, 2006, pp. 02-03. 61

ATIENZA, Manuel. "El derecho como argumentación”. In: ATIENZA, Manuel \& FERRAJOLI, Luigi. Jurisdicción y argumentación en el Estado constitucional de derecho. São Paulo: Landy, 2000, p. 72.
} 
ALEXY, Robert. Teoria dos direitos fundamentais. Tradução de Virgílio Afonso da Silva. São Paulo: Malheiros, 2008.

ATIENZA, Manuel. "El derecho como argumentación”. In: ATIENZA, Manuel \& FERRAJOLI, Luigi. Jurisdicción y argumentación en el Estado constitucional de derecho. São Paulo: Landy, 2000.

BARROSO, Luís Roberto. O Controle de Constitucionalidade no Direito Brasileiro. 2 ed. São Paulo: Saraiva, 2006.

DWORKIN, Ronald. Taking Rights Seriously. 2 ed. Londres: Duckworth, 1978.

FERREIRA, Fernando Galvão de Andréa. “O discurso jurídico como discurso prático: aspectos do debate entre Robert Alexy e Jürgen Habermas”. In: Revista da Faculdade de Direito de Campos, ano VII, $\mathrm{n}^{\circ} 9$ - dezembro de 2006.

HABERMAS, Jürgen. Between Facts and Norms: contributions to a discourse theory of law and democracy. Tradução de William Rehg. Cambrigde: MIT, 1996.

HABERMAS, Jürgen. "Reply to Symposium Participants". In: ROSENFELD, Michel e ARATO, Andrew (eds.). Habermas on Law and Democracy. Los Angeles e Londres: Berkeley, 1998.

LARENZ, Karl. Methodenlehre der Rechtswissenschaft. Berlim: Springer-Verlag, 1991.

LARENZ, Karl. Metodologia Jurídica. Lisboa: Calouste Gulbenkian, 1989.

PERELMAN, Chaïm e OLBRECHTS-TYTECA, Lucie. La nouvelle rhétorique: Traité de l'argumentacion. Paris, 1958. 2 ed. Inalterada Brüssel, 1970.

SAVIGNY, Friedrich Carl von. System des heutigen Römischen Rechts. vol. I. Berlim, 1840 . 
Quaestio Iuris vol.05, no 01. ISSN 1516-0351

STAUB, Hermann. Die positiven Vertragsverletzungen. 2 ed. Berlim, 1913.

VILANOVA, Lourival. Causalidade e Relação no Direito. 4 ed. São Paulo: RT, 2000. 